Original Research

\title{
Fractures and Chronic Recurrence are Commonly Associated with Ankle Sprains: a 5-year Population-level Cohort of Patients Seen in the U.S. Military Health System
}

\author{
Daniel I Rhon ${ }^{1} \odot{ }^{\text {a }}$, Tina A Greenlee ${ }^{2} \odot$, Chad E Cook ${ }^{3} \odot$, Richard B Westrick', Jon A Umlauf ${ }^{3}$, John J Fraser ${ }^{5} \odot$ \\ ${ }^{1}$ Military Performance Division, United States Army Research Institute of Environmental Medicine; Department of Rehabilitation Medicine, Brooke \\ Army Medical Center, ${ }^{2}$ Rehabilitation Medicine, Brooke Army Medical Center, ${ }^{3}$ Department of Orthopaedic Surgery, Duke University School of \\ Medicine, ${ }^{4}$ Military Performance Division, US Army Research Institute of Environmental Medicine, ${ }^{5}$ Directorate for Operational Readiness \& Health, \\ Naval Health Research Center \\ Keywords: epidemiology, tactical athlete, injury severity, ankle sprain, ankle fracture, military medicine \\ https://doi.org/10.26603/001c.27912
}

\section{International Journal of Sports Physical Therapy}

Vol. 16, Issue 5, 2021

\begin{abstract}
Background
Whereas ankle-foot injuries are ubiquitous and affect $~ 16 \%$ of military service-members, granularity of information pertaining to ankle sprain subgroups and associated variables is lacking. The purpose of this study was to characterize and contextualize the burden of ankle sprain injuries in the U.S. Military Health System.
\end{abstract}

\section{Methods}

This was a retrospective cohort study of beneficiaries seeking care for ankle sprains, utilizing data from the Military Health System Data Repository from 2009 to 2013. Diagnosis and procedural codes were used to identify and categorize ankle sprains as isolated lateral, isolated medial, concomitant medial/lateral, unspecified, or concomitant ankle sprain with a malleolar or fibular fracture. Patient characteristics, frequency of recurrence, operative cases, and injury-related healthcare costs were analyzed.

\section{Results}

Of 30,910 patients included, $68.4 \%$ were diagnosed with unspecified ankle sprains, $22.8 \%$ with concomitant fractures, (6.9\%) with isolated lateral sprains, (1.7\%) with isolated medial sprains and $0.3 \%$ with combined medial/lateral sprains. Pertaining to recurrence, $44.2 \%$ had at least one recurrence. Sprains with fractures were $\sim 2-4$ times more likely to have surgery within one year following injury (36.2\% with fractures; $9.7 \%$ with unspecified sprains) and had the highest ankle-related downstream costs.

\section{Conclusion}

Fractures were a common comorbidity of ankle sprain (one in five injuries), and operative care occurred in $16.4 \%$ of cases. Recurrence in this cohort approximates the $40 \%$ previously reported in individuals with first-time ankle sprain who progress to chronic ankle instability. Future epidemiological studies should consider reporting on subcategories of ankle sprain injuries to provide a more granular assessment of the distribution of severity.

\footnotetext{
a Corresponding Author:

Daniel Rhon

Primary Care Musculoskeletal Research Department of Rehabilitation Medicine Brooke Army Medical Center 3551 Roger Brooke Drive JBSA Fort Sam Houston, TX 78234 PH: 210-916-6100Fax: 210-916-9016 daniel.i.rhon.ctr@mail.mil
} 


\section{Level of evidence}

$3 b$

\section{BACKGROUND}

Ankle-foot injuries are ubiquitous and one of the most common injuries, particularly in individuals who engage in physical activity and sport. The largest single contributor to all reported injuries in collegiate athletes was ankle sprains (14.8\%), occurring at a consistent rate of 0.83 per 1000 athlete exposures between 1988 and $2004 .^{1}$ In military service members, who experience considerable physical demands and are required to function in diverse environments, ankle-foot injuries can substantially curtail the ability to complete duty requirements and operational objectives. Anklefoot injuries were the third leading factor of lost work time of the US Armed Forces in 2002, ${ }^{2}$ and by 2017-2018 they were ranked first for all U.S. Army soldiers. ${ }^{3}$ Among ankle foot-injuries, lateral ankle sprains (LAS) are among the most common. 4

The rate of ankle sprains in military personnel $(\sim 35$ per 1000 person-years $)^{4,5}$ is nearly five times greater than that reported in the civilian population. ${ }^{6}$ While several epidemiological studies have assessed the incidence of ankle sprains in military populations, ${ }^{4,7-9}$ none have provided treatment fidelity and contextualized morbidity (e.g. persistence of symptoms, recurrence, type and severity of injury). This is especially problematic since injury pathomechanics and the resulting ankle-foot neuromusculoskeletal impairments following ankle sprain are highly variable. ${ }^{10}$ Outcomes such as health care utilization, cost, and length of disability are likely mediated by injury severity and concomitant conditions. For example, presence of a comorbid fracture may complicate management of the injury and lead to a protracted recovery.

Recurrence of ankle sprains is also common in military members ${ }^{11}$ with repeat injuries occurring anywhere from two weeks to eight years or more following the index sprain. ${ }^{12}$ There is inconsistency in the reported rates of ankle injury recurrence, a consequence that is likely attributed to methodological heterogeneity and relatively short follow-up periods employed by most studies. ${ }^{13}$ In the first study to prospectively assess long term outcomes following a first-time lateral ankle sprain evaluated in a civilian emergency department, $40 \%$ of these individuals progressed to develop chronic ankle instability (CAI) ${ }^{14}$ a complex and heterogeneous neuromusculoskeletal condition characterized by episodic or perceived instability of the ankle that results in activity limitation and participation restriction at least 12 months following injury. ${ }^{15}$ While the prevalence of CAI in the military is currently unknown, it is highly plausible that the burden is similar to that found among the general populous. Epidemiological studies are currently underway to substantiate this supposition.

In the 2021 revision of the ankle instability clinical practice guideline put forth by the American Academy of Orthopaedic Physical Therapy, the authors emphasized the importance of evaluating and contextualizing granular examination findings following LAS to aid in prognostication and when developing individualized care plans. ${ }^{10}$ In the same context and applied at a more macro level, greater granularity for contextualizing burden is needed to properly plan medical staffing and resource requirements to mitigate the impact of ankle sprains and optimize recovery following injury. ${ }^{5}$ Therefore, the purpose of this study was to characterize and contextualize the burden of ankle sprain injuries in the U.S. Military Health System. A secondary aim was to assess disparities in healthcare utilization and costs stratified by ankle injury type.

\section{METHODS}

This was a retrospective cohort study of all beneficiaries of the U.S. Military Health System that assessed ankle injury burden, stratified by injury type, in a five-year epoch. Ethics approval was provided by the Institutional Review Board at Brooke Army Medical Center (Research Evidence Level 3b). The REporting of studies Conducted using Observational Routinely collected health Data (RECORD) statement from the STROBE checklist was used to guide reporting. ${ }^{16}$

\section{DATA SOURCE}

Data were sourced from the US Military Health System Data Repository (MDR) using billed diagnosis (International Classification of Diseases, 9th edition [ICD-9-CM]) and procedure (Current Procedural Terminology ${ }^{\circledR}$ [CPT]) codes. The MDR contains validated data derived from medical encounters provided within the Department of Defense's (DoD) worldwide network of more than 260 health care facilities and from the TRICARE Purchased Care program. It is a closed, single-payer government health system of all active and retired military members, their families, and other affiliated beneficiaries. More information about the MDR can be accessed at health.mil.

\section{COHORT SELECTION}

Individuals diagnosed with an ankle sprain with and without concomitant fracture between 01 January 2009 and 31 December 2012 were included in this study, regardless of whether they were active-duty, retired service members or dependents. Anyone under the age of 18 or over the age of 50 was also excluded, to best capture the age range of most military service members. Rank and military service is based on the sponsor status (individual on active duty). Table 1 details the diagnosis codes used to identify the respective cases. To ensure included injuries were an initial diagnosis or episode, individuals diagnosed with an anklefoot injury or surgery in the 12 months prior were excluded from analysis. Individuals that were not diagnosed with an ankle sprain or had an isolated fibular fracture, a fracture of the tibia or fibula superior to the malleoli or sustained an injury less than 12 months before the end of the study epoch were excluded from analysis. Figure 1 details the case selection in the identified cohort. 
Table 1. Diagnosis Codes Used for Cohort Selection

\begin{tabular}{|c|c|}
\hline Code & Description \\
\hline 845.00 & Sprain of ankle, unspecified site \\
\hline 845.01 & Sprain of deltoid (ligament), ankle \\
\hline 845.02 & Sprain of calcaneofibular (ligament) of ankle \\
\hline 845.03 & Sprain of tibiofibular (ligament), distal of ankle \\
\hline 845.09 & Other sprains and strains of ankle \\
\hline 824.0 & Fracture of medial malleolus, closed \\
\hline 824.1 & Fracture of medial malleolus, open \\
\hline 824.2 & Fracture of lateral malleolus, closed \\
\hline 824.3 & Fracture of lateral malleolus, open \\
\hline 824.4 & Bimalleolar fracture, closed \\
\hline 824.5 & Bimalleolar fracture, open \\
\hline 824.6 & Trimalleolar fracture, closed \\
\hline 824.7 & Trimalleolar fracture, open \\
\hline 824.8 & Unspecified fracture of ankle, closed \\
\hline 824.9 & Unspecified fracture of ankle, open \\
\hline
\end{tabular}

Values represent codes from the International Classification of Diseases and Related Health Problems (ICD), $9^{\text {th }}$ Edition

\section{OUTCOME VARIABLES}

A 60-day period without any foot or ankle related care, followed by an encounter for an ankle-related injury, was considered a new injury episode. These criteria have been previously employed to define discrete episodes of care, ${ }^{17}$ and can be considered a proxy for symptom recurrence or re-injury. Total costs for all encounters with an ankle-foot related diagnosis or procedure in the follow-up period were calculated and cases that required surgery or sought urgent care during the same timeframe were identified. Each distinct case was classified in only one category (i.e., an individual with a concomitant fracture was only counted once in that injury category). The actual cost of claims incurred by the DHA for care obtained in civilian network clinics and DHA-assigned costs for all encounters and procedures for care in military treatment facilities were utilized to determine costs of ankle-related care; both of which are provided in the MDR.

\section{DATA INTEGRITY}

Because the MHS is a single payer closed health system, the MDR is a robust data repository with few missing data. The MDR receives continuous data inputs in "RAW" form which are continuously validated for a minimum of 90 days through cross-referencing of other data sources, before the variable converts from "RAW" to "FINAL". Absence of healthcare utilization data in the MDR implies either that servicemembers did not experience these injuries or could have sustained an injury but self-managed (non-care seeking behaviors) following injury. While less than $3 \%$ of beneficiaries were found to have supplemental health insurance listed in the MDR, the widespread presence of billed encounters for ankle sprain indicates they are likely relying on their primary coverage for the care of this condition. ${ }^{18}$

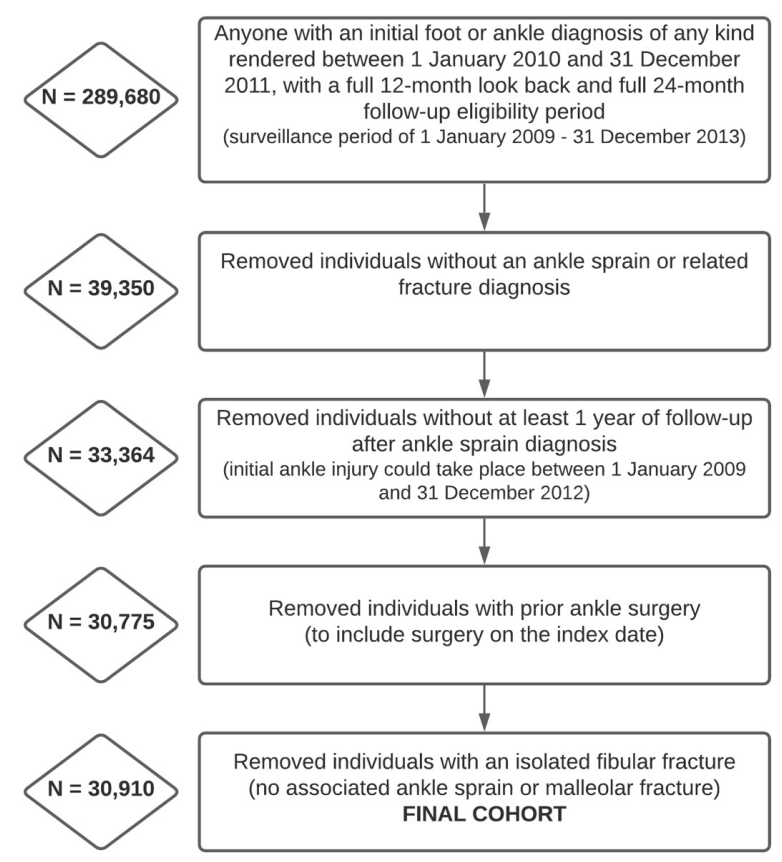

Figure 1. Flow of Cohort Selection

Active-duty service members are much less likely to have other health insurance as all their medical needs are prioritized in the MHS, at zero cost to them.

\section{RESULTS}

There were 289,680 unique individuals with an ankle-foot musculoskeletal injury identified during the study epoch. 
After isolating the cohort to only ankle sprain related injuries and applying exclusion criteria (Figure 1), there were 30,910 unique individuals remaining in the final cohort (mean age: $31.7 \pm 8.9$, male sex: $60.8 \%$, active-duty service component: $63.2 \%$ ). The mean time a case was available for follow-up in this dynamic cohort was $729 \pm 147$ days, with a median of 730 days. The follow-up times did not substantially differ between the injury subgroups. Almost one quarter of all cases $(22.8 \%, n=7049)$ were diagnosed with a fracture. The generic diagnosis "unspecified ankle sprain” was employed for most individuals $(68.4 \%$; $n=21,135)$. A small proportion of the cohort had the specific diagnoses of isolated lateral sprain $(6.9 \% ; n=2128)$ or isolated medial sprain $(1.7 \% ; n=513)$, and less than one percent $(0.3 \% ; n=85)$ were diagnosed with a combined medial and lateral sprain (Figure 2). Service members who served in the Army, were junior enlisted, and on active duty accounted for the largest proportion of cases with ankle injuries (Table 2).

About half of all cases (55.9\%) had only a single episode of medical care (any kind, to include rehabilitation), 41.4\% had two to four distinct care episodes, and $2.8 \%$ had five or more distant episodes following the index injury (Table 2 ). This means that $44.1 \%$ of the entire cohort had at least one recurrence. Cases that had a sprain with concomitant fracture had the highest mean costs (USD \$4161 \pm 656 ), with cases that had both medial and lateral complex injury had the highest one-year median costs $(\$ 1924)$. Sprains that were unspecified had the lowest median one-year cost (USD \$780). Compared to the other injuries, cases that experienced a sprain with fractures were up to four times more likely to have surgery during the surveillance period (36.2\%) compared to the other categories. The group with the fewest surgeries was the unspecified sprain group (9.7\%). Patients with a concomitant fracture were also the most likely compared to any other group to have had an urgent care visit associated with their injury (4.5\%). Approximately $41.9 \%$ of individuals received physical rehabilitation interventions to manage their ankle injury (i.e., exercise, therapeutic modalities, manual therapy), with the mean days to the first rehabilitation intervention being 72.6 (Table 2).

\section{DISCUSSION}

The primary finding of this study was that recurrence of ankle sprain post injury approximated the $40 \%$ previously reported in individuals with first-time ankle sprain who progress to chronic ankle instability. ${ }^{14}$ Fractures were a common comorbidity (one in five injuries), and operative care occurred in $16.4 \%$ of cases. Regardless of ankle injury diagnosis and complexity, more than half of individuals did not receive rehabilitation care following injury. Of the individuals who received care by a rehabilitation specialist, there was a substantially protracted delay from the time of injury to the first visit (mean of 72.6 days). This is the first study to have assessed and qualified population-level burden of ankle injuries at this level, with concomitant multimorbidity in the military. This is also innovative since this is also one of the first to report healthcare cost and utilization of rehabilitation services of ankle injuries within the US Military Health System. The mean healthcare cost for the treatment of ankle injuries was similar to the care of

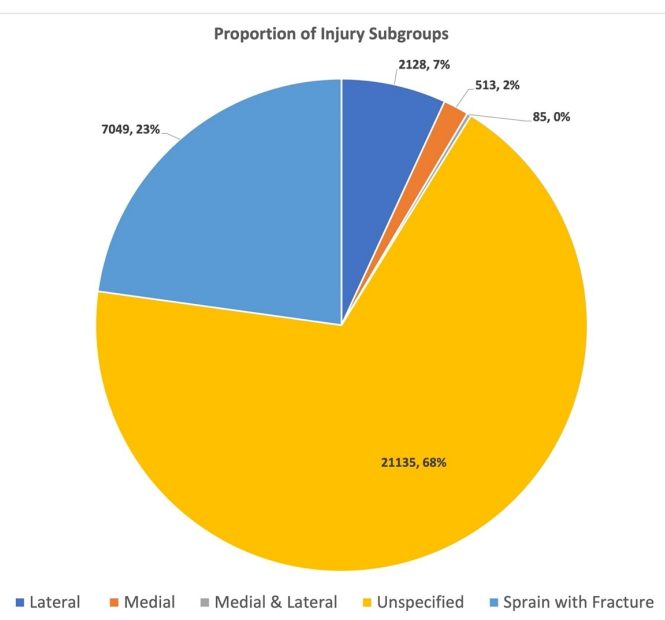

Figure 2. Proportion within ankle injury subgroups

service members with low back pain, the leading sources of burden and cost in the Military Health System. ${ }^{19,20}$

Several previous studies have reported the burden of ankle sprain injuries in the military. One report found that 423,581 service members sustained an ankle sprain at a rate of 34.9 per 1000 person-years from 1998 to $2006 .{ }^{4}$ Between 2000 and 2006, 16\% of all US Army soldiers sought care for an ankle sprain. ${ }^{21}$ In a more recent epidemiological study assessing lateral ankle sprain risk in the military, 360,256 service members incurred this injury from 2006 to 2015 at a rate of 28.8 per 1000 person-years in enlisted members and 13.2 per 1000 person-years in military officers. ${ }^{5}$ It is therefore no surprise to see the number of service members with these injuries and the substantial burden these injuries placed on the military health system. Considering there are a large subset of service members who do not seek care for ankle sprains, the true burden is likely even larger. ${ }^{22}$

Females in this study comprised $37.7 \%$ of the cohort, and approximately one third (29.3\%) of the females were on active duty (11.1\% of the total cohort; $21.2 \%$ of those on active duty), a proportion slightly higher than that of the population at risk (in 2019, female service members comprised $16.9 \%$ of the force). ${ }^{23}$ There are a few reasons this is likely. Female sex has been found to be a non-modifiable intrinsic risk factor for lateral ankle sprains, especially in the athletic population ${ }^{24}$ This finding was similarly observed in service members across most military occupations, with female service members found to be 1.09 to 1.68 more likely to be diagnosed with an ankle sprain. This was also observed in another study where female service members were $21 \%$ more likely to sustain an ankle sprain than their male counterparts. ${ }^{4}$ These findings are likely attributed, in part, to footwear choices, hormonal influences, and differences in joint phenotypes observed in females. ${ }^{5}$ This may also be attributed to greater care seeking in females, ${ }^{5}$ a factor that is quite plausibly mediated by cultural influences in the military. $^{22}$

The mean age of this study cohort $(31.7 \pm 8.9$ years $)$ and specifically for those on active duty (30.4 \pm .4 years), generally reflected that of the military population as a whole (mean age in $2019=28.2$ ). ${ }^{23}$ While the cohort includes de- 
Table 2. Summary of Patient and Healthcare Utilization Characteristics Between Ankle Injury Subgroups

\begin{tabular}{|c|c|c|c|c|c|c|}
\hline \multirow[b]{2}{*}{ Variable } & \multirow[b]{2}{*}{$\begin{array}{l}\text { Total } \\
\text { Ankle } \\
\text { Injuries } \\
\mathrm{N}=30,910\end{array}$} & \multicolumn{5}{|c|}{ Initial Ankle Injury Type } \\
\hline & & $\begin{array}{l}\text { Isolated } \\
\text { Lateral } \\
\text { Sprain } \\
n=2128 \\
(6.9 \%)\end{array}$ & $\begin{array}{l}\text { Isolated } \\
\text { Medial } \\
\text { Sprain } \\
n=513 \\
(1.7 \%)\end{array}$ & $\begin{array}{l}\text { Medial and } \\
\text { Lateral } \\
\text { Sprain } \\
n=85 \\
(0.3 \%)\end{array}$ & $\begin{array}{l}\text { Unspecified } \\
\text { Sprain }{ }^{\dagger} \\
n=21,135 \\
(68.4 \%)\end{array}$ & $\begin{array}{l}\text { Sprain with } \\
\text { Ankle } \\
\text { Fracture } \\
\mathrm{n}=7049 \\
(22.8 \%)\end{array}$ \\
\hline Male Sex, n (p) & $\begin{array}{l}18,626 \\
(60.8)\end{array}$ & $\begin{array}{l}1364 \\
(64.7)\end{array}$ & 308 (60.7) & $52(62.7)$ & $\begin{array}{l}12,367 \\
(59.1)\end{array}$ & 4535 (64.4\%) \\
\hline Mean Age (SD) & $31.7(8.9)$ & $31.8(8.5)$ & $32.7(9.1)$ & $32.4(9.3)$ & $31.5(8.8)$ & $32.3(9.2)$ \\
\hline \multicolumn{7}{|l|}{ Age Groups, n (p') } \\
\hline $18-30$ & $\begin{array}{l}15,343 \\
(49.6)\end{array}$ & $\begin{array}{l}1060 \\
(49.8)\end{array}$ & 225 (43.9) & $41(48.2)$ & $\begin{array}{l}10,623 \\
(85.9)\end{array}$ & 3394 (48.1) \\
\hline $31-40$ & $\begin{array}{l}9327 \\
(30.2)\end{array}$ & $662(31.1)$ & $164(32.0)$ & $22(25.9)$ & $6437(30.5)$ & $2042(29.0)$ \\
\hline $41+$ & $\begin{array}{l}6238 \\
(20.2)\end{array}$ & 406 (19.1) & $124(24.2)$ & $22(25.9)$ & 4074 (19.3) & $1612(22.9)$ \\
\hline \multicolumn{7}{|l|}{ Military Status, n (p) } \\
\hline Active Duty & $\begin{array}{l}19,520 \\
(63.2)\end{array}$ & $\begin{array}{l}1552 \\
(72.9)\end{array}$ & 305 (59.5) & $53(62.4)$ & $\begin{array}{l}13,200 \\
(62.5)\end{array}$ & $4410(62.6)$ \\
\hline Retired & $\begin{array}{l}1588 \\
(5.1)\end{array}$ & $83(3.9)$ & $34(6.6)$ & $4(4.7)$ & $998(4.7)$ & $469(6.7)$ \\
\hline $\begin{array}{l}\text { Family Member/ } \\
\text { Dependent }\end{array}$ & $\begin{array}{l}9506 \\
(30.8)\end{array}$ & $474(22.3)$ & $166(32.4)$ & $26(30.6)$ & $6665(31.5)$ & $2075(29.4)$ \\
\hline Other/Unknown & $396(1.3)$ & $19(0.9)$ & $8(1.6)$ & $2(2.4)$ & $272(1.3)$ & $95(1.3)$ \\
\hline \multicolumn{7}{|l|}{ Service Branch, n (p') } \\
\hline Army & $\begin{array}{l}12,812 \\
(41.4)\end{array}$ & $950(44.6)$ & 185 (36.1) & $36(42.4)$ & $8776(41.5)$ & $2865(40.6)$ \\
\hline Air Force & $\begin{array}{l}8773 \\
(28.4)\end{array}$ & $658(30.9)$ & $143(27.9)$ & $27(31.8)$ & $6130(29.0)$ & $1815(25.7)$ \\
\hline Navy & $\begin{array}{l}5207 \\
(16.8)\end{array}$ & $294(13.8)$ & $93(18.1)$ & $13(15.3)$ & $3457(16.4)$ & $1350(19.2)$ \\
\hline Marine Corps & $\begin{array}{l}2641 \\
(8.5)\end{array}$ & $136(6.4)$ & $58(11.3)$ & $4(4.7)$ & $1736(8.2)$ & 707 (10.0) \\
\hline Coast Guard & $\begin{array}{l}1018 \\
(3.3)\end{array}$ & $66(3.1)$ & $24(4.7)$ & $3(3.5)$ & $725(3.4)$ & $200(2.8)$ \\
\hline Other/Unknown & $459(1.5)$ & $24(1.1)$ & $10(1.9)$ & $2(2.4)$ & $311(1.5)$ & $112(1.6)$ \\
\hline \multicolumn{7}{|l|}{ Rank, n (ṕ) } \\
\hline Cadets & $195(0.6)$ & $26(1.2)$ & $5(1.0)$ & 0 & $116(0.5)$ & $48(0.7)$ \\
\hline Junior Enlisted & $\begin{array}{l}18,621 \\
(60.2)\end{array}$ & $\begin{array}{l}1275 \\
(59.9)\end{array}$ & $282(55.0)$ & $47(55.3)$ & $\begin{array}{l}12,851 \\
(60.8)\end{array}$ & $4166(59.1)$ \\
\hline Senior Enlisted & $\begin{array}{l}6572 \\
(21.3)\end{array}$ & $411(19.3)$ & $127(24.8)$ & $24(28.2)$ & $4483(21.2)$ & $1527(21.7)$ \\
\hline Junior Officer & $\begin{array}{l}2400 \\
(7.8)\end{array}$ & $192(9.0)$ & $40(7.8)$ & $5(5.9)$ & $1610(7.6)$ & $553(7.8)$ \\
\hline Senior Officer & $\begin{array}{l}2732 \\
(8.8)\end{array}$ & $205(9.6)$ & $51(9.9)$ & $7(8.2)$ & $1807(8.5)$ & $662(9.4)$ \\
\hline Other/Unknown & $390(1.3)$ & $19(0.9)$ & $8(1.6)$ & $2(2.4)$ & $268(1.3)$ & $93(1.3)$ \\
\hline $\begin{array}{l}\text { Distinct Episodes of } \\
\text { Care Mean (SD) } \\
\text { [median] }\end{array}$ & $\begin{array}{l}1.76(1.1) \\
{[1.0]}\end{array}$ & $\begin{array}{l}1.9(1.2) \\
{[2.0]}\end{array}$ & $\begin{array}{l}1.9(1.2) \\
{[1.0]}\end{array}$ & $\begin{array}{l}1.9(1.1) \\
{[2.0]}\end{array}$ & $\begin{array}{l}1.7(1.1) \\
{[1.0]}\end{array}$ & 1.9 (1.1) [1.0] \\
\hline \multicolumn{7}{|l|}{ Frequency, n (ṕ) } \\
\hline 1 & $\begin{array}{l}17,268 \\
(55.9)\end{array}$ & $\begin{array}{l}1034 \\
(48.6)\end{array}$ & $275(53.6)$ & $41(48.2)$ & $\begin{array}{l}12,338 \\
(58.4)\end{array}$ & $3580(50.8)$ \\
\hline 2 & $\begin{array}{l}7604 \\
(24.6)\end{array}$ & $573(26.9)$ & $126(24.6)$ & $23(27.1)$ & $4954(23.4)$ & $1928(27.4)$ \\
\hline
\end{tabular}




\begin{tabular}{|c|c|c|c|c|c|c|}
\hline \multirow[b]{2}{*}{ Variable } & \multirow[b]{2}{*}{$\begin{array}{l}\text { Total } \\
\text { Ankle } \\
\text { Injuries } \\
\mathrm{N}=30,910\end{array}$} & \multicolumn{5}{|c|}{ Initial Ankle Injury Type ${ }^{*}$} \\
\hline & & $\begin{array}{l}\text { Isolated } \\
\text { Lateral } \\
\text { Sprain } \\
n=2128 \\
(6.9 \%)\end{array}$ & $\begin{array}{l}\text { Isolated } \\
\text { Medial } \\
\text { Sprain } \\
n=513 \\
(1.7 \%)\end{array}$ & $\begin{array}{l}\text { Medial and } \\
\text { Lateral } \\
\text { Sprain } \\
\mathrm{n}=85 \\
(0.3 \%)\end{array}$ & $\begin{array}{l}\text { Unspecified } \\
\text { Sprain }{ }^{\dagger} \\
n=21,135 \\
(68.4 \%)\end{array}$ & $\begin{array}{l}\text { Sprain with } \\
\text { Ankle } \\
\text { Fracture } \\
\mathrm{n}=7049 \\
(22.8 \%)\end{array}$ \\
\hline 3 & $\begin{array}{l}3541 \\
(11.5)\end{array}$ & $292(13.7)$ & 60 (11.7) & $15(17.6)$ & $2286(10.8)$ & $888(12.6)$ \\
\hline 4 & $\begin{array}{l}1643 \\
(5.3)\end{array}$ & $160(7.5)$ & $30(5.8)$ & $3(3.5)$ & $1025(4.8)$ & $425(6.0)$ \\
\hline $5+$ & $854(2.8)$ & $69(3.2)$ & $22(4.3)$ & $3(3.5)$ & $532(2.5)$ & $228(3.2)$ \\
\hline $\begin{array}{l}\text { Ankle-Related ED } \\
\text { Visits, } n(p)\end{array}$ & $430(1.4)$ & $6(0.3)$ & $2(0.4)$ & 0 & $101(0.5)$ & $321(4.5)$ \\
\hline $\begin{array}{l}\text { Physical Rehabilitation, } \\
n\left(p^{\prime}\right)\end{array}$ & $\begin{array}{l}12,963 \\
(41.9)\end{array}$ & $\begin{array}{l}1176 \\
(55.3)\end{array}$ & $250(48.7)$ & $51(60.0)$ & $8066(38.2)$ & $3420(48.5)$ \\
\hline $\begin{array}{l}\text { Time to Physical } \\
\text { Rehabilitation } \\
\text { Evaluation (days), Mean } \\
\text { (SD) [median] }\end{array}$ & $\begin{array}{l}110.0 \\
(158.6) \\
{[50.0]}\end{array}$ & $\begin{array}{l}90.5 \\
(145.6) \\
{[35.0]}\end{array}$ & $\begin{array}{l}102.1 \\
(150.0) \\
{[41.0]}\end{array}$ & $\begin{array}{l}53.0(59.6) \\
{[32.0]}\end{array}$ & $\begin{array}{l}116.6 \\
(170.0) \\
{[35.0]}\end{array}$ & $\begin{array}{l}103.2(135.5) \\
{[62.0]}\end{array}$ \\
\hline $\begin{array}{l}\text { Time to Physical } \\
\text { Rehabilitation } \\
\text { Intervention (days), } \\
\text { Mean (SD) [median] }\end{array}$ & $\begin{array}{l}72.6 \\
(181.0) \\
{[37.0]}\end{array}$ & $\begin{array}{l}58.8 \\
(182.2) \\
{[25.0]}\end{array}$ & $\begin{array}{l}42.2 \\
(182.9) \\
{[22.5]}\end{array}$ & $\begin{array}{l}60.2 \\
(148.4) \\
{[29.0]}\end{array}$ & $\begin{array}{l}71.5(195.5) \\
{[27.0]}\end{array}$ & $\begin{array}{l}82.3(141.1) \\
{[57.0]}\end{array}$ \\
\hline Ankle Surgeries, $n\left(p^{*}\right)$ & $\begin{array}{l}5072 \\
(16.4)\end{array}$ & 389 (18.3) & $61(11.9)$ & $16(18.9)$ & $2052(9.7)$ & $2554(36.2)$ \\
\hline $\begin{array}{l}\text { Healthcare Cost per } \\
\text { Patient-Year (USD), } \\
\text { Mean (SD) [median] }\end{array}$ & $\begin{array}{l}\$ 2725 \\
(5052) \\
{[1003]}\end{array}$ & $\begin{array}{l}\$ 3256 \\
(4834) \\
{[1408]}\end{array}$ & $\begin{array}{l}\$ 2807 \\
(4231) \\
{[1284]}\end{array}$ & $\begin{array}{l}\$ 3430 \\
(3927) \\
{[1924]}\end{array}$ & $\begin{array}{l}\$ 2188 \\
(4368) \\
{[780]}\end{array}$ & $\begin{array}{l}\$ 4161 \\
(6569) \\
{[1808]}\end{array}$ \\
\hline
\end{tabular}

ED, Emergency Department; SD, standard deviation.

Note: *Individuals are present only once in each category, which defaults to the more specific or more severe category (e.g., if someone had a lateral ankle sprain and a fracture, they were included only in the fracture count); †Unspecified can include both medial and lateral sprains, as well as syndesmotic sprains (high ankle). $\hat{p}=$ proportion within group

pendents and retirees, the cohort selection parameters were set to exclude anyone over the age of 50 (mean age for retired service members in this cohort was $44.7 \pm 4.9)$. However, this finding is disparate from previous studies that have identified younger age as a risk factor. This may be attributed, in part, as a function of exposure. In the civilian sector, participation in physical activity and athletic competition is voluntary and typically performed by younger individuals. In the military, engaging in high levels of physically demanding tasks is compulsory and tied to military requirements. This finding may also be attributed to agerelated disparities in care-seeking behaviors and perceived access to care, a supposition that will need to be elucidated in future research.

Almost one quarter of all cases (22.8\%) in this study were diagnosed with a fracture. This finding is consistent with a previous study that found the prevalence of fractures to be approximately $22 \%$ of all inversion ankle injuries. ${ }^{25}$ In a separate study of civilian beneficiaries with private health insurance, $67.8 \%$ of all individuals with ankle sprain received imaging, with only $7.3 \%$ of individuals with ankle sprain found to have a fracture. ${ }^{26}$ The disparity between the observations in this study and those reported by Feger and colleagues ${ }^{26}$ is likely attributed to differences in careseeking behaviors and a function of grit, resilience, and other psychosocial factors specific to the military. ${ }^{22}$ Due to the morbidity associated with more severe injuries such as fractures, a service member is likely to be more compelled to seek care following injury. This is stark contrast to ankle sprains, where self-management, injury minimization, and perceptions of "it is only an ankle sprain" is pervasive among service members. ${ }^{22}$

One key finding to highlight is the high prevalence of ankle sprain recurrence in this cohort. Almost half of all cases (44.1\%), regardless of injury type, had at least one recurrence within one year following injury. This finding is likely attributed to persistent symptoms, ankle impairment, and activity limitation that persisted beyond 60 days following the index injury. Almost one in five (19.6\%) cases had three or more care episodes, indicating that symptoms and disability persisted for at least 120 days following injury. These values align with reports in civilian populations showing that as high as $40 \%$ of individuals proceed to have chronic ankle instability. ${ }^{27}$ While the methodology employed in this study does not allow for determination of a chronic ankle instability diagnosis, ${ }^{15}$ it does provide the foundation to develop epidemiological approaches to define the condition when chronicity persists beyond 12 months following index injury, an effort that is currently underway. This highlights the idea that care seeking for recurrent ankle sprains within the first year of injury may be a useful indicator for predicting long term morbidity in service members. The cases that experienced recurrence most likely reflected a higher injury severity or persistence, reaching a threshold where 
the individual felt the need to seek care. It is likely that any preconceived beliefs and attitudes of ankle sprains as selflimiting are challenged when self-resolution does not occur, which necessitates care-seeking. Furthermore, social determinants of care-seeking may radically shift when a service member is unable to complete their duties when recalcitrant ankle-foot impairment, activity limitation, and participation restriction preclude execution of the unit mission. It is not uncommon for service members to be directed to seek medical care by their command leadership when activity limitation is observed.

In this cohort $41.9 \%$ of cases were referred to a rehabilitation specialist following injury, a proportion that is substantially higher than the $11 \%$ reported in a large study of civilian beneficiaries covered by private insurance. ${ }^{28}$ Among the minority of individuals who were referred for physical rehabilitation following ankle sprain in this cohort, a protracted delay in care was observed; a finding that is similarly observed in the civilian healthcare sector. ${ }^{26}$ This is likely attributed to the predominant traditional referralbased model utilized in the Military Health System, relatively small number of rehabilitation specialists available to provide care, and perceived or actual barriers to care. While clinicians in the military health system are doing substantially better than their civilian counterparts, this pattern of care is still suboptimal. More than half of service members with ankle injuries captured in this study were seen by primary care providers, a service that typically provides medication and general instructions for self-management. Referral to specialty care, such as rehabilitation specialists, is typically delayed until patients return to the clinic with reports of persistent pain and impairment. Considering the substantial physical requirements placed on service members and that the proportion of individuals who progress to develop chronic ankle instability and long-term disability is not declining, increased and more timely access to rehabilitation specialists is warranted. ${ }^{22}$ This is especially salient since there is very strong evidence that rehabilitation care improves functional outcomes and health-related quality of life, more rapidly returns individuals back to work and sport, and reduces injury recurrence in the long term. ${ }^{29}$

\section{CLINICAL \& RESEARCH IMPLICATIONS}

Based on the substantial risk, associated morbidity, and healthcare costs associated with ankle sprain observed in this study, a radical shift in the management of ankle sprain in the Military Health System should occur. Shifting the traditional mindset of ankle sprain mostly being a minor and self-limiting condition is a substantial barrier that needs to be overcome. Education of both military healthcare providers and the military communities they serve is needed to overcome gaps in knowledge, beliefs, and attitudes toward injury and treatment and facilitate culture change. ${ }^{22}$ Implementation of interdisciplinary teams, including rehabilitation specialists, on the primary care level with operational military units is also warranted to address the varying complexity of ankle injuries, reduce barriers and delay of care, and facilitate a more rapid return to function. ${ }^{5,22}$ Health services research is needed to empirically assess the effectiveness of more contemporary health deliv- ery approaches in the military.

With the evidence of increased risk of recurrent ankle sprain during the first year following injury, it behooves clinicians to employ prophylactic measures to mitigate secondary injury. There is strong evidence for the employment of ankle braces, which are cost effective, and balance exercises for the secondary prevention of injury following ankle sprain. ${ }^{10,29}$ Since it is not uncommon for individuals with ankle sprain to have perceived or episodic instability within the first 12 months following injury, ${ }^{14}$ clinicians should consider use of prophylactic bracing during this period, especially when service members are required to function in austere environments or during high risk activities (parachute jumping, marching on unimproved or improved surfaces or through foliage, when carrying external loads, etc.). Based on the prevalence of recurrence and healthcare cost per patient reported this study and operating under the assumption that ankle braces cost approximately $\$ 25$ and that service members will be fully compliant and regularly wear the device, a $\$ 154,550$ per annum investment in ankle brace prophylaxis would translate to a cost savings of $\$ 7.4$ million per annum. While compliance will likely be realistically much lower, 30 the return on investment in terms of healthcare cost savings and improved operational readiness is still substantial if only a fraction of these patients employ prophylaxis the year following injury. Future study of the effectiveness of braces on primary and secondary ankle prophylaxis in the military is warranted. Furthermore, study of the form, fit, and function of ankle braces among service members in different military occupations may also elucidate factors that may influence compliance with prophylaxis.

Prospective study of cohorts with recent ankle injuries with specific emphasis on variability in treatment response between the ankle sprain subgroups is also encouraged. Exploration of practice patterns in this patient population and consistency with current clinical guidelines would be of value, in addition to the intervention's greatest reduction in persistent morbidity and healthcare costs is also needed. A more comprehensive approach to managing a variety of types of ankle sprain injuries in the military may help to minimize disability and maximize return to duty. Lastly, due to the potential for ankle sprain to affect the long-term health of military service members, ${ }^{22}$ methodological development of epidemiological estimations of chronic ankle instability in the military population and study of the longterm burden and effect on health-related quality of life is warranted.

\section{STRENGTHS AND LIMITATIONS}

The main strength of this study is the large size of the sample. This is a closed health system which reflects high fidelity with data capture and almost no missing data (little to no care delivered outside the TRICARE footprint). At the same time, that can also be a limitation as the results may not be generalizable to other settings. This is the first study characterizing injury severity based on healthcare utilization variables. A limitation is that most variables were determined from diagnosis and procedure codes entered by clinicians into electronic medical records and are subject to 
the limitations inherent with this type of data (variability in use of diagnostic codes, etc.). Many individuals could have sustained an ankle sprain and not sought care or not had the requisite of 12-month minimum follow-up required for inclusion. Therefore, the rates of ankle sprain injuries are likely much higher. The majority of ankle sprains were coded as non-specific, limiting the assumptions that can be made about subgroups, and highlighting the importance and need for more precise diagnostic coding by providers in the MHS. Comfort can be taken knowing lateral ligament injuries represent $92 \%$ of all ankle sprains. ${ }^{31}$ With the wax and wane of military operations and ongoing changes in healthcare delivery, the external validity of these findings may be limited and may not necessarily reflect the current and future burden of these injuries. However, there is no evidence to suggest that the problem of ankle sprains has changed much over the last decade, and in fact the most recent reports show it continues to be extremely pervasive. ${ }^{32}$ There is an inability to assess laterality of injury with ICD-9 codes. It is plausible that individuals experience a recurrence in the contralateral limb. While possible, these research findings are still substantial since bilateral deficits are common following ankle sprain. ${ }^{33}$ Estimates of burden in this study were derived from healthcare visits. Based on the prior evidence of self-management, injury minimization, and psychosocial determinants of care-seeking, it is likely that the burden is substantially greater than that reported in this study. ${ }^{22}$

\section{CONCLUSION}

Ankle sprains in a military population were primarily diagnosed using non-specific codes. Fractures were a common comorbidity, which warrants routine clinical examination (approximately 1 in 5 injuries included a fracture). Almost half of all patients (44.1\%) had at least one recurrent episode following the initial injury. These recurrence rates approximate the $40 \%$ previously reported in individuals with first-time ankle sprain who progress to chronic ankle instability. Very few cases were seen in an urgent care setting (1.4\%). For treatment $16.4 \%$ underwent surgical care and $41.9 \%$ had at least one associated physical rehabilitation procedure. Future epidemiological studies should consider reporting on subcategories of ankle sprain injuries to provide a more granular assessment of the distribution of severity. This can allow for assessment of treat- ment response variability within injury subgroups and improved precision for targeted interventions.

\section{COMPETING AND CONFLICTING INTEREST}

No authors have any competing or conflicts of interest to declare

\section{FUNDING}

This research was supported by the Department of Defense Clinical Rehabilitation Medical Research Program (CRMRP) Award \#W81XWH-18-1-0788, under program number W81XWH-17-DMRDP-CRMRP-NMSIRRA) and in part by an appointment to the Department of Defense (DOD) Research Participation Program administered by the Oak Ridge Institute for Science and Education (ORISE) through an interagency agreement between the U.S. Department of Energy (DOE) and the DOD. ORISE is managed by ORAU under DOE contract number DE-SC0014664.

\section{DISCLAIMER}

The view(s) expressed herein are those of the author(s) and do not necessarily reflect the official policy or position of Brooke Army Medical Center, the U.S. Army Office of the Surgeon General, the Department of the Army, the Department of the Navy, the Defense Health Agency, the Department of Defense, nor the U.S. Government. The authors are military service members or employees of the U.S. Government, and this work was prepared as part of their official duties. Title 17, USC, §105 provides that 'Copyright protection under this title is not available for any work of the U.S. Government.' Title 17, USC, §101 defines a U.S. Government work as a work prepared by a military service member or employee of the U.S. Government as part of that person's official duties. The study protocol was approved by the Brooke Army Medical Center Institutional Review Board in compliance with all applicable Federal regulations governing the protection of human subjects. Research data were derived from an approved Brooke Army Medical Center Institutional Review Board protocol, number C.2016.048n.

Submitted: April 16, 2021 CDT, Accepted: August 05, 2021 CDT 


\section{REFERENCES}

1. Hootman JM, Dick R, Agel J. Epidemiology of collegiate injuries for 15 sports: Summary and recommendations for injury prevention initiatives. $J$ Athl Train. 2007;42(2):311-319.

2. Brundage JF, Johnson KE, Lange JL, Rubertone MV. Comparing the population health impacts of medical conditions using routinely collected health care utilization data: Nature and sources of variability. Mil Med. 2006;171(10):937-942. doi:10.7205/milmed.17 1.10 .937

3. Roy TC, Faller TN, Richardson MD, et al. Characterization of limited duty neuromusculoskeletal injuries and return to duty times in the U.S. Army during 2017-2018. Mil Med. January 2021. doi:10.1093/milmed/usaa392

4. Cameron KL, Owens BD, DeBerardino TM. Incidence of ankle sprains among active-duty members of the United States armed services from 1998 through 2006. J Athl Train. 2010;45(1):29-38. do $\mathrm{i}: 10.4085 / 1062-6050-45.1 .29$

5. Fraser JJ, MacGregor AJ, Ryans CP, Dreyer MA, Gibboney MD, Rhon DI. Sex and occupation are salient factors associated with lateral ankle sprain risk in military tactical athletes. J Sci Med Sport. 2021;24(7):677-682. doi:10.1016/j.jsams.2021.02.016

6. Waterman BR, Owens BD, Davey S, Zacchilli MA, Belmont PJ. The epidemiology of ankle sprains in the United States. J Bone Joint Surg Am.

2010;92(13):2279-2284. doi:10.2106/jbjs.i.01537

7. Gerber JP, Williams GN, Scoville CR, Arciero RA, Taylor DC. Persistent disability associated with ankle sprains: A prospective examination of an athletic population. Foot Ankle Int. 1998;19(10):653-660. doi:1 $\underline{0.1177 / 107110079801901002}$

8. Waterman BR, Belmont PJ, Cameron KL, DeBerardino TM, Owens BD. Epidemiology of ankle sprain at the United States Military Academy. Am J Sports Med. 2010;38(4):797-803. doi:10.1177/0363546 $\underline{509350757}$

9. Waterman BR, Belmont PJJr, Cameron KL, Svoboda SJ, Alitz CJ, Owens BD. Risk factors for syndesmotic and medial ankle sprain: Role of sex, sport, and level of competition. Am J Sports Med. 2011;39(5):992-998. doi:10.1177/0363546510391462
10. Martin RL, Davenport TE, Fraser JJ, et al. Ankle stability and movement coordination impairments: Lateral ankle ligament sprains revision 2021. J Orthop Sports Phys Ther. 2021;51(4):CPG1-CPG80. doi:10.251 9/jospt.2021.0302

11. Orr JD, Robbins J, Waterman BR. Management of chronic lateral ankle instability in military service members. Clin Sports Med. 2014;33(4):675-692. doi:1 0.1016/j.csm.2014.06.011

12. van Rijn RM, van Os AG, Bernsen RMD, Luijsterburg PA, Koes BW, Bierma-Zeinstra SMA. What is the clinical course of acute ankle sprains? A systematic literature review. Am J Med. 2008;121(4):324-331.e7. doi:10.1016/j.amimed.2007.1 $\underline{1.018}$

13. Petersen W, Rembitzki IV, Koppenburg AG, et al. Treatment of acute ankle ligament injuries: A systematic review. Arch Orthop Trauma Surg. 2013;133(8):1129-1141. doi:10.1007/s00402-013-174 2-5

14. Doherty C, Bleakley C, Hertel J, Caulfield B, Ryan J, Delahunt E. Recovery from a first-time lateral ankle sprain and the predictors of chronic ankle instability: A prospective cohort analysis. Am J Sports Med. 2016;44(4):995-1003. doi:10.1177/0363546516628870

15. Hertel J, Corbett RO. An updated model of chronic ankle instability. J Athl Train. 2019;54(6):572-588. do i:10.4085/1062-6050-344-18

16. Benchimol EI, Smeeth L, Guttmann A, et al. The REporting of studies conducted using observational routinely-collected health data (RECORD) statement. PLoS Med. 2015;12(10):e1001885. doi:10.1371/journa l.pmed.1001885

17. Stahlman S, Taubman SB. Incidence of acute injuries, active component, U.S. armed forces, 2008-2017. MSMR. 2018;25(7):2-9.

18. Rhon DI, Clewley D, Young JL, Sissel CD, Cook CE. Leveraging healthcare utilization to explore outcomes from musculoskeletal disorders: Methodology for defining relevant variables from a health services data repository. BMC Med Inform Decis Mak. 2018;18(1). do i:10.1186/s12911-018-0588-8

19. Rhon DI, Miller RB, Fritz JM. Effectiveness and downstream healthcare utilization for patients that received early physical therapy versus usual care for low back pain: A randomized clinical trial. Spine. 2018;43(19):1313-1321. doi:10.1097/brs.00000000000 $\underline{02619}$ 
20. Childs JD, Fritz JM, Wu SS, et al. Implications of early and guideline adherent physical therapy for low back pain on utilization and costs. BMC Health Serv Res. 2015;15(1). doi:10.1186/s12913-015-0830-3

21. Wallace RF, Wahi MM, Hill OT, Kay AB. Rates of ankle and foot injuries in active-duty U.S. Army soldiers, 2000-2006. Mil Med. 2011;176(3):283-290. ․ oi:10.7205/milmed-d-10-00098

22. Fraser JJ, Schmied E, Rosenthal MD, Davenport TE. Physical therapy as a force multiplier: Population health perspectives to address short-term readiness and long-term health of military service members. Cardiopulm Phys Ther J. 2020;31(1):22-28. doi:10.109 7/cpt.0000000000000129

23. Office of the Deputy Assistant Secretary of Defense for Military Community and Family Policy (ODASD (MC\&FP)). 2019 Demographics profile of the military community. Department of Defense. http s://download.militaryonesource.mil/12038/MOS/Repo rts/2019-demographics-report.pdf. Published 2020.

24. Delahunt E, Remus A. Risk factors for lateral ankle sprains and chronic ankle instability. J Athl Train. 2019;54(6):611-616. doi:10.4085/1062-6050-44-18

25. Khor YP, Tan KJ. The anatomic pattern of injuries in acute inversion ankle sprains: A magnetic resonance imaging study. Orthop J Sports Med. 2013;1(7):2325967113517078.

26. Feger MA, Glaviano NR, Donovan L, et al. Current trends in the management of lateral ankle sprain in the United States. Clin J Sport Med. 2016;0:1-8.
27. Hershkovich O, Tenenbaum S, Gordon B, et al. A large-scale study on epidemiology and risk factors for chronic ankle instability in young adults. J Foot Ankle Surg. 2015;54(2):183-187. doi:10.1053/j.jfas.2014.06.0 $\underline{01}$

28. Feger MA, Herb CC, Fraser JJ, Glaviano N, Hertel J. Supervised rehabilitation versus home exercise in the treatment of acute ankle sprains: A systematic review. Clin Sports Med. 2015;34(2):329-346. doi:10.1 016/i.csm.2014.12.001

29. Vuurberg G, Hoorntje A, Wink LM, et al. Diagnosis, treatment and prevention of ankle sprains: Update of an evidence-based clinical guideline. $\mathrm{Br} \mathrm{J}$ Sports Med. 2018;52(15):956. doi:10.1136/bjsports-20 $\underline{17-098106}$

30. Knapik JJ, Spiess A, Swedler D, et al. Injury risk factors in parachuting and acceptability of the parachute ankle brace. Aviat Space Environ Med. 2008;79(7):689-694. doi:10.3357/asem.2273.2008

31. Shah S, Thomas AC, Noone JM, Blanchette CM, Wikstrom EA. Incidence and cost of ankle sprains in United States emergency departments. Sports Health. 2016;8(6):547-552. doi:10.1177/1941738116659639

32. Molloy JM, Pendergrass TL, Lee IE, Chervak MC, Hauret KG, Rhon DI. Musculoskeletal injuries and United States Army readiness part I: Overview of injuries and their strategic impact. Mil Med. 2020;185(9-10):e1461-e1471. doi:10.1093/milmed/us aa027

33. Wikstrom EA, Naik S, Lodha N, Cauraugh JH. Bilateral balance impairments after lateral ankle trauma: A systematic review and meta-analysis. Gait Posture. 2010;31(4):407-414. doi:10.1016/j.gaitpost.2 010.02.004 